\title{
Soluble Adhesion Molecules and Cytokines in Children Affected by Recurrent Infections of the Upper Respiratory Tract
}

\author{
GRAZIA MALAPONTE, VALENTINA BEVELACQUA, GIOVANNI LI VOLTI, \\ MARCELLO PETRINA, GIUSY NICOTRA, VALENTINA SAPUPPO, SALVATORE LI VOLTI, \\ SALVATORE TRAVALI, AND MARIA CLORINDA MAZZARINO \\ Department of Biomedical Sciences, Section of General Pathology [G.M., V.B., M.P., G.N., M.C.M.], \\ Department of Biomedical Sciences, Section of Clinical Pathology and Molecular Oncology [S.T.], and \\ Department of Pediatrics [G.L.V., S.L.V.], Faculty of Medicine, University of Catania, 95124 Catania, Italy
}

\begin{abstract}
The objective of this study was to compare plasma levels of soluble adhesion molecules and Th1-Th2 type cytokines in 44 children with frequently recurrent respiratory infections (FRRI) of upper airways, defined as having nine or more episodes per year, and in 34 children without recurrence; all subjects were followed-up for 12 mo. The viral etiology was determined by cultures from nasal, pharyngeal, and ear secretions, using PCR and immunofluorescence. Plasma levels of five soluble adhesion molecules (E-selectin, P-selectin, L-selectin, intercellular adhesion molecule-1, and vascular cell adhesion molecule-1) and interferon (IFN)- $\gamma$, IL-12, IL-4, and IL-10 were measured in patients and in 15 healthy controls using sandwich ELISA. During acute phase, all patients showed significant increase in plasma levels of soluble adhesion molecules; during the followup, the levels were greater in children with FRRI. A difference of cytokine profile was demonstrated between the patients with and without FRRI: an increased IL-4 and IL-10 release with decreased levels of IFN- $\gamma$ and IL-12 suggested a skewing into
\end{abstract}

\section{ABSTRACT}

Th2-type response, in patients with FRRI. This pattern persisted during the follow-up. In patients without recurrence, an increased IFN- $\gamma$ and IL-12 release, together with decreased levels of IL-4 and IL-10, showed a skewing into Th1-type responses; in the follow-up these cytokines reached normal values. In conclusion, the abnormal levels of all examined parameters in children with FRRI may reflect the persistence of an inflammatory microenvironment in the airways and an activation of the immune system that may contribute to the frequently recurrence of the respiratory disease. (Pediatr Res 55: 666-673, 2004)
Abbreviations
FRRI, frequently recurrent respiratory infections
URTI, upper respiratory tract infections
CAM, cellular adhesion molecule
sVCAM-1, soluble vascular cell adhesion molecule-1
sICAM-1, soluble intercellular adhesion molecule-1
IFN, interferon

Infections of the URTI are the most common cause of viral morbidity in children. They represent the most frequent managed problem in general pediatric practice (1) and are responsible for more than one third of school absences (2). Many different immunologic problems can concur to the development of respiratory infections (3). Disorders of the aspecific humoral and the specific cellular defense are the principal cause of inflammation in the upper respiratory diseases (4). The recruitment and activation of inflammatory cells at the site of infection involve the expression of leukocyte and vascular

Received May 27, 2003; accepted November 4, 2003.

Correspondence: Grazia Malaponte, M.D., Department of Biomedical Sciences, Section of General Pathology, Via Androne 83, 95124 Catania, Italy; e-mail: G.malaponte@mbox.unict.it

Supported by a grant from Ministero dell' Universìtá, Ricerca Scientifica e Technologica (G.M.).

DOI: 10.1203/01.PDR.0000113770.22794.DF adhesion molecules and the generation of pro-inflammatory cytokines, which contribute to the injury of lung epithelial and endothelial barriers (5). An important role in the early transient adhesion phases of leukocytes is mediated by the selectin family, which includes three distinct carbohydrate receptors expressed by either endothelial cells (E-selectin), leukocytes (L-selectin), or platelets and endothelial cells (P-selectin) (6). ICAM-1 and VCAM-1 are membrane glycoproteins, belonging to the immunoglobulin superfamily; ICAM-1 are widely expressed on respiratory epithelial cells, monocytes, macrophages, dendritic cells, and, together with VCAM-1, on vascular endothelial cells $(7,8)$. These adhesion molecules, after a proteolytic cleavage, are found as soluble forms in the circulation (8). Patients with systemic inflammation present elevated levels of soluble adhesion molecules and the measurement of their levels is considered useful in the evaluation of inflammatory disorders $(9-11)$. Thus, soluble adhesion mole- 
cules could indicate the state of activation of adhesion molecules and regulate the adherence of leukocytes to the endothelial cells (8). However, little is known about the functional role of adhesion molecules in respiratory tract infections.

Various cytokines up-regulate adhesion molecules on both endothelial and epithelial cells, thereby enhancing migration of leukocytes into the mucosa and causing aberrant immune regulation within the epithelium $(5,12)$.

In the complex cytokine network, IFN- $\gamma$, IL-12, IL-4, and IL-10 play an important role in responses to viral infections (13), regulating the Th-1/Th-2 balance (14).

The aim of this study was, first, to measure plasma levels of soluble adhesion molecules (sL-selectin, sE-selectin, sPselectin, sICAM-1, and sVCAM-1) and Th-1/Th-2 cytokines in the plasma of children during URTI and to compare these levels in children with or without FRRI. Secondly, we sought to evaluate the role of the adhesion molecules and cytokines to ascertain whether anomalies in the immune response to viral infections are associated with subsequent development and recurrence of URTI.

\section{METHODS}

Study subjects. This study included 78 children ( 38 girls, 40 boys) affected by URTI who were referred to the Day Hospital of the Pediatric Department of the University of Catania and who completed the follow-up. Written informed consent was obtained for all patients and controls, from the parents during the enrollment visit. Moreover, the study protocol was approved by the University Medical Ethics Committee. The inclusion criteria into this study were as follows: i) recurrent URTI characterized by fever $>38^{\circ} \mathrm{C}$ for $3-6 \mathrm{~d}$, rhinorrhea, sinusitis, otitis, pharyngitis, laryngitis, and mild cough; ii) normal findings at $\mathrm{x}$-ray examination of the chest during the acute phase of URTI; iii) no recognized primary or secondary immunodeficiency (no leukopenia with neutropenia, no serum low levels of $\gamma$-globulins, normal subsets of both $\mathrm{T}$ and $\mathrm{B}$ cells); iv) no signs of malnutrition; v) no treatment with glucocorticoid or antibiotic drugs at both the baseline visit and at least $2 \mathrm{wk}$ before the admission to this study; and vi) neither history of asthma nor allergic disorders before entering this study. For the purpose of the current study, the patients were arbitrarily divided into two groups according to the number of episodes of URTI per year. Group 1 included 44 children $(26$ males, 18 females) of age ranging from 2 to 6 y (mean $3.40 \pm$ 1.31) who suffered from at least nine episodes of recurrent URTI per year (FRRI). Group 2 included 34 children (14 males, 20 females) of age ranging from 2 to $6 \mathrm{y}$ (mean $3.53 \pm$ 1.35) who had experienced fewer than nine episodes of URTI per year.

History of recurrent URTI was obtained directly from each child's parent(s), who recorded in a diary the number and the clinical characteristics of every episode of URTI.

Moreover, they were studied during the acute phase of infections $\left(\mathrm{T}_{0}\right)$, and the monitoring was performed at $6\left(\mathrm{~T}_{1}\right)$ and $12\left(\mathrm{~T}_{2}\right)$ mo, respectively. Acute phase was considered to be from d 1 to $\mathrm{d} 3$ after the onset of symptoms; during the acute phase, children were only under antipyretic treatment. During the follow-up period, no symptom of infection was present. Routine laboratory tests, including C-reactive protein, erythrocyte sedimentation rate, and leukocyte count, were performed for each patient. Samples of blood and cultures from nasal, pharyngeal, and ear secretions to detect virus infections or exclude bacterial infections were obtained from the children during the visits. During these patient-initiated visits, patient history was obtained and a physical examination was performed. A control group consisted of 15 healthy children ( 9 boys, 6 girls), whose ages ranged from 2 to 5.5 y (mean $3.2 \pm$ 1.1 , and who were free from manifest allergic diseases, immune and hematological disorders and hospitalized in the Pediatric Orthopedics Department.

Blood sample collection. Venous blood samples were collected from all patients with URTI and from normal controls in two sterile tubes: one with EDTA for the assay of lymphocyte subpopulations, for the determination of the soluble adhesion molecules and for cytokine assays; and another without anticoagulants for the determination of immunoglobulins.

Plasma was immediately separated by centrifugation at 400 $\times g$ for 15 min at $4^{\circ} \mathrm{C}$ and divided in aliquots. An aliquot was immediately used for lymphocyte subpopulation assay. The remaining aliquots were stored at $-80^{\circ} \mathrm{C}$ and used for the soluble adhesion molecules and cytokine assays. For each subject, samples were collected at baseline $\left(T_{0}\right)$ and at $6\left(T_{1}\right)$ and $12\left(\mathrm{~T}_{2}\right)$ mo after the monitoring.

Quantitation of Ig. Ig and IgG subclasses were quantified by a nephelometric method (Beckman nephelometer, BeckmanCoulter, Fullerton, CA, U.S.A.).

Lymphocyte subpopulations. The relative sizes of $\mathrm{T}$-cell $\left(\mathrm{CD}_{3}{ }^{+}, \mathrm{CD}_{4}{ }^{+}, \mathrm{CD}_{8}{ }^{+}\right)$and HLA-DR in activated $\mathrm{CD}_{3}{ }^{+}$and B-cell populations $\left(\mathrm{CD}_{19}{ }^{+}, \mathrm{CD}_{5}{ }^{+}, \mathrm{CD}_{16}{ }^{+}\right)$were analyzed with MAb (BD Biosciences, San Jose, CA, U.S.A.) by cytofluorimetry (FacScan, BD Biosciences).

Soluble adhesion molecules and cytokines assays. sLselectin, sE-selectin, sP-selectin, sICAM-1, and sVCAM-1 and all cytokine (IFN- $\gamma$, IL-12, IL-4, and IL-10) levels were determined by a sandwich ELISA technique. Commercially available kits from Bender MedSystems (Vienna, Austria) were used for soluble adhesion molecules, and kits from $\mathrm{R} \& \mathrm{D}$ Systems (Minneapolis, MN, U.S.A.) were used for IFN- $\gamma$, IL-12, IL-4, and IL-10. Procedures were performed according to the manufacturer's instructions. All measurements were performed in triplicate. The sensitivity limits were as follows: sE-selectin, $6.5 \mathrm{ng} / \mathrm{mL}$; sL-selectin, $0.3 \mathrm{ng} / \mathrm{mL}$; sP-selectin, 1.3 $\mathrm{ng} / \mathrm{mL}$; sICAM-1, $0.5 \mathrm{ng} / \mathrm{mL}$; sVCAM- $1,0.9 \mathrm{ng} / \mathrm{mL}$; IFN- $\gamma, 8$ $\mathrm{pg} / \mathrm{mL} ; \mathrm{IL}-12,5 \mathrm{pg} / \mathrm{mL}$; IL-4, $10 \mathrm{pg} / \mathrm{mL}$; and IL-10, 3.9 $\mathrm{pg} / \mathrm{mL}$.

Cell culture isolation. Cultures were obtained from nasal, pharyngeal, and ear secretions from all patients. Two samples from the nasal secretion-one from each nostril, one from the pharyngeal-and from ear secretions were taken. A sterile nylon brush was placed on the nasal, pharyngeal mucosa and in the external acoustic meatus, and removed gently without anesthesia. Every brush was immediately placed in a closed container that contained viral transport medium, placed on ice, and sent immediately to the laboratory where every medium with suspended cells was centrifuged for $15 \mathrm{~min}$ and inoculated in four 
cell lines (American Type Culture Collection, Manassas, VA, U.S.A.) in tube cultures while remaining aliquot was frozen at $-70^{\circ} \mathrm{C}$ until tested by PCR human lung carcinoma cells (A549), HeLa Ohio cells, Madin-Darby kidney cells, and LLC-MK2 cells, and for adenovirus, rhinovirus, influenza virus, and parainfluenza viruses 1,2 and 3 cell cultures and virus cytopathic effects were performed as described by Billaud et al. (15).

Detection of viruses by PCR. PCR reaction was performed for adenovirus, rhinovirus, influenza virus, and parainfluenza viruses 1, 2, and 3 using validated techniques. Briefly, DNA and RNA extraction was performed on $0.1 \mathrm{~mL}$ of cell suspension using the QIAamp blood and viral DNA/RNA kit (QIAGEN GmbH, Hilden, Germany), according to the manufacturer's instructions. In particular, for the adenovirus an aliquot of DNA was prepared according to the method suggested by Marin et al. (16). For rhinovirus, the aliquots of RNA samples were reversed in two cDNA according to the method of Steininger et al. (17). For the detection of influenza A virus, we used the methods of Steininger et al. (18). For the influenza B virus, a rapid single-step RT-PCR assay was carried out according to the method of Daum et al. (19). For the detection of parainfluenza viruses 1,2 , and 3 , we used the method described by Corne et al. (20). All RT-PCR and PCR were performed using a PE 9700 thermocycler (PerkinElmer Life Science, Boston, MA, U.S.A.). Amplified products ( $5 \mu \mathrm{L})$ after PCR (adenovirus) and RT-PCR (rhinovirus, virus influenza A and B, parainfluenza viruses 1,2 , and 3 ) were separated by electrophoresis and visualized under UV using ethidium bromidetreated $(1 \mu \mathrm{g} / 10 \mathrm{~mL}) 2.0 \%$ agarose gels.

Statistical analysis. Statistical analysis was performed with the SPSS version 6.1 software package (SPSS Inc., Chicago, IL, U.S.A.). Differences in levels of circulating adhesion molecules and cytokines between normal controls and patients, with and without recurrent URTI, were tested for significance using a Mann-Whitney $U$ test. Data analyzed within subjects were analyzed using two-way ANOVA. Correlations between variables were analyzed using Spearman's rank-order correlation coefficient. Each result was calculated as a mean \pm SEM. $p$ Values $<0.05$ were considered statistically significant.

\section{RESULTS}

Children and URTI. The demographic and clinical data of the children studied are shown in Table 1. There were no

Table 1. Patient's baseline characteristics

\begin{tabular}{lccc}
\hline & Controls & Without FRRI & FRRI \\
\hline Evaluable patients $(n)$ & 15 & 34 & 44 \\
Sex (M/F) & $9 / 6$ & $14 / 20$ & $25 / 19$ \\
Age mean (range) & $3.2 \pm 1.11$ & $3.4 \pm 1.31$ & $3.5 \pm 1.29$ \\
Incidence of fever $\left(>38^{\circ}\right)$ & & & \\
$\quad$ Baseline & - & 34 & 44 \\
After 6 mo & - & 0 & 0 \\
After 12 mo & - & 0 & 0 \\
Respiratory infections & & & \\
$\quad$ Pharyngitis & - & 12 & 15 \\
Laryngitis & - & 15 & 20 \\
Otitis & - & 7 & 9 \\
\hline
\end{tabular}

significant differences in the age and sex between the children with or without FRRI. The distribution of pathogens is shown in Table 2. Rhinovirus, influenza A virus, and adenovirus were detected most often in patients with URTI. The greatest incidence of URTI was caused by influenza A epidemics, which occurred in late winter, and adenovirus, which occurred throughout the year.

Quantitation of Ig and lymphocyte subpopulations. Figure 1 shows IgG, IgM, IgA, and IgE serum levels (Fig. $1 A$ ) and IgG subclasses (Fig. $1 B$ ) in normal controls and in children with and without frequently recurrent URTI. Significantly higher total IgG were found in both group 1 patients compared with normal controls $(p=0.0001)$ and in group 2 patients compared with normal controls $(p=0.001)$. In contrast, other classes of $\operatorname{Ig}$, including $\operatorname{IgE}$ at $\mathrm{T}_{0}, \mathrm{~T}_{1}$, and $\mathrm{T}_{2}$, in both groups,

Table 2. Viruses analysis in nasal, pharyngeal, and ear secretion cultures from children with URTI

\begin{tabular}{cl}
\hline Patients $(n=78)$ & Nasal, pharyngeal, and ear cultures \\
\hline 14 & Rhinovirus \\
25 & Adenovirus* \\
27 & Influenza A virus \\
8 & Influenza B virus \\
4 & Parainfluenza viruses 1,2 , and 3 \\
\hline
\end{tabular}

Results of cultures were confirmed by * PCR and RT-PCR analysis as described in "Methods."
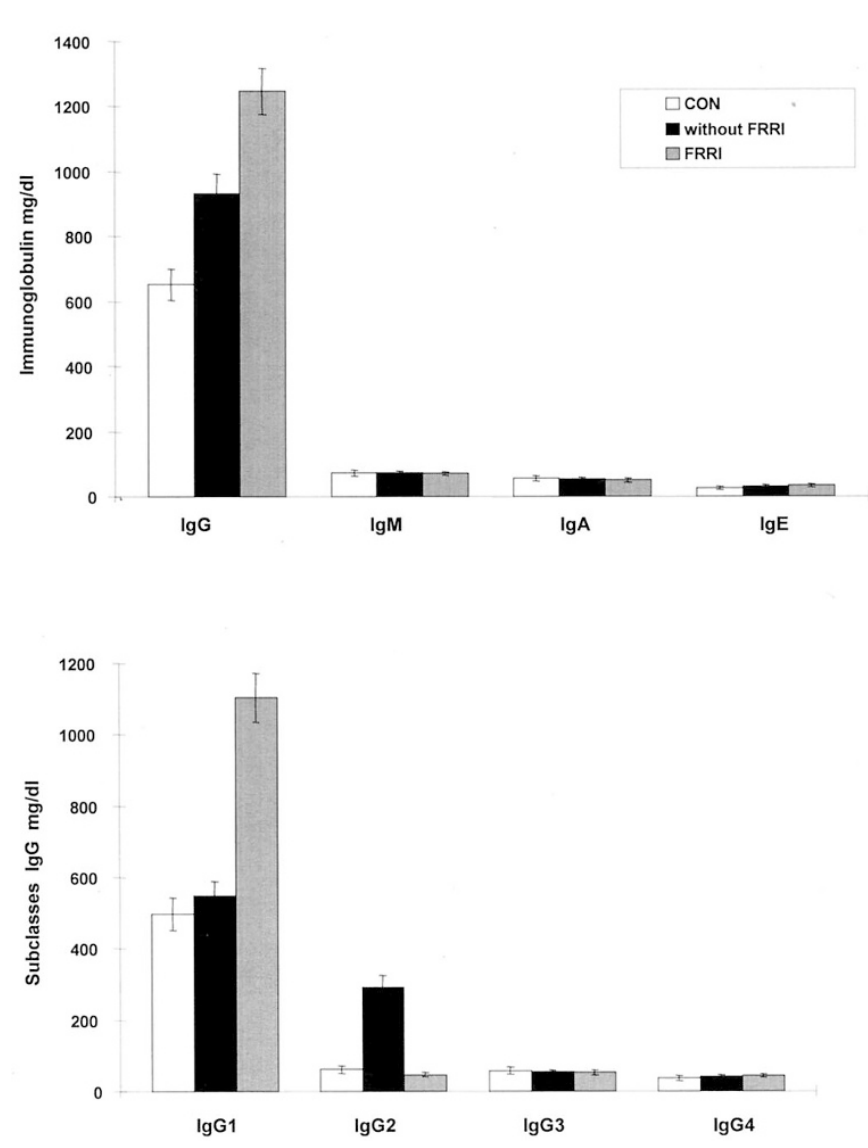

Figure 1. Serum $\operatorname{Ig}(A)$ and $\operatorname{IgG}$ subclasses $(B)$ in normal controls $(C O N)$ and in patients with and without FRRI. The values are expressed as means \pm SEM. 
did not show statistically significant differences when compared with each other and to normal controls (data not shown). Moreover, plasma levels of $\operatorname{IgG}_{1}$ isotype antibodies were higher in patients with FRRI (group 1) compared with patients without recurrence (group 2) and normal controls ( $p=$ $0.0001)$, whereas the $\operatorname{IgG}_{2}$ isotype response was slightly decreased, suggesting a predominance of the Th-2-type response. In contrast, patients in group 2 showed an opposite trend. Plasma levels of $\mathrm{IgG}_{2}$ isotype antibodies were higher in patients without recurrence compared with patients with FRRI and normal controls $(p=0.0001)$, whereas the $\operatorname{IgG}_{1}$ isotype response was statistically decreased $(p=0.0001)$, suggesting a predominance of the Th1-type response. Normal levels of $\operatorname{IgG}_{3}$ and $\mathrm{IgG}_{4}$ isotype antibodies were found in all groups of subjects. During the follow-up period, the IgG total and subclasses of $\mathrm{IgG}_{1}$ and $\mathrm{IgG}_{2}$ isotype antibodies returned to normal levels in all groups (data not shown).

Lymphocyte subpopulations, in all patients and in normal controls, were of normal size and there were no statistically significant differences (data not shown).

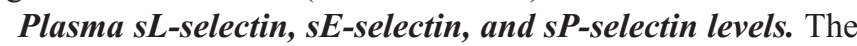
mean values of plasma levels of sL-, sE-, and sP-selectins from normal controls and from children with and without FRRI, during the acute phase of infection $\left(\mathrm{T}_{0}\right)$ and $6 \mathrm{mo}\left(\mathrm{T}_{1}\right)$ and 12 mo later $\left(\mathrm{T}_{2}\right)$ are shown in Figure 2. At $\mathrm{T}_{0}$, sL-selectin (Fig. $2 A$ ), sE-selectin (Fig. $2 B$ ), and sP-selectin (Fig. $2 C$ ) in children with FRRI were significantly higher than in normal controls ( $p$ $=0.0001)$ and persisted at elevated levels at both $T_{1}$ and $T_{2}$, with a $p$ value ranging from 0.001 to 0.0001 . Although selectin plasma levels decreased slightly during the follow-up, the difference did not reach statistical significance.

At $\mathrm{T}_{0}$, plasma levels of sL-, sE- and sP-selectins in patients without recurrence were significantly higher than in normal controls ( $p=0.019, p=0.003$, and, $p=0.002$, respectively). These values, during the monitoring, decreased, reaching normal levels. In each group, statistically significant differences were found in the soluble selectins at $\mathrm{T}_{0}, \mathrm{~T}_{1}$, and $\mathrm{T}_{2}(p=$ 0.0001).

The comparison between both study groups demonstrated higher release of selectins in children with FRRI (group 1) than in group 2 , at $\mathrm{T}_{0}, \mathrm{~T}_{1}$ and $\mathrm{T}_{2}$, with a $p$ value ranging from 0.017 to 0.0001 .

Plasma levels of sICAM-1 and SVCAM-1. Figure 3 shows plasma levels of sICAM-1 (Fig. 3A) and sVCAM-1 (Fig. 3B) in children with and without FRRI and in normal controls. Plasma levels of sICAM-1 and sVCAM-1 were very high in patients with FRRI at $\mathrm{T}_{0}$ when compared with normal controls $(p=0.0001)$; at $\mathrm{T}_{1}$ and $\mathrm{T}_{2}$, they decreased but remained
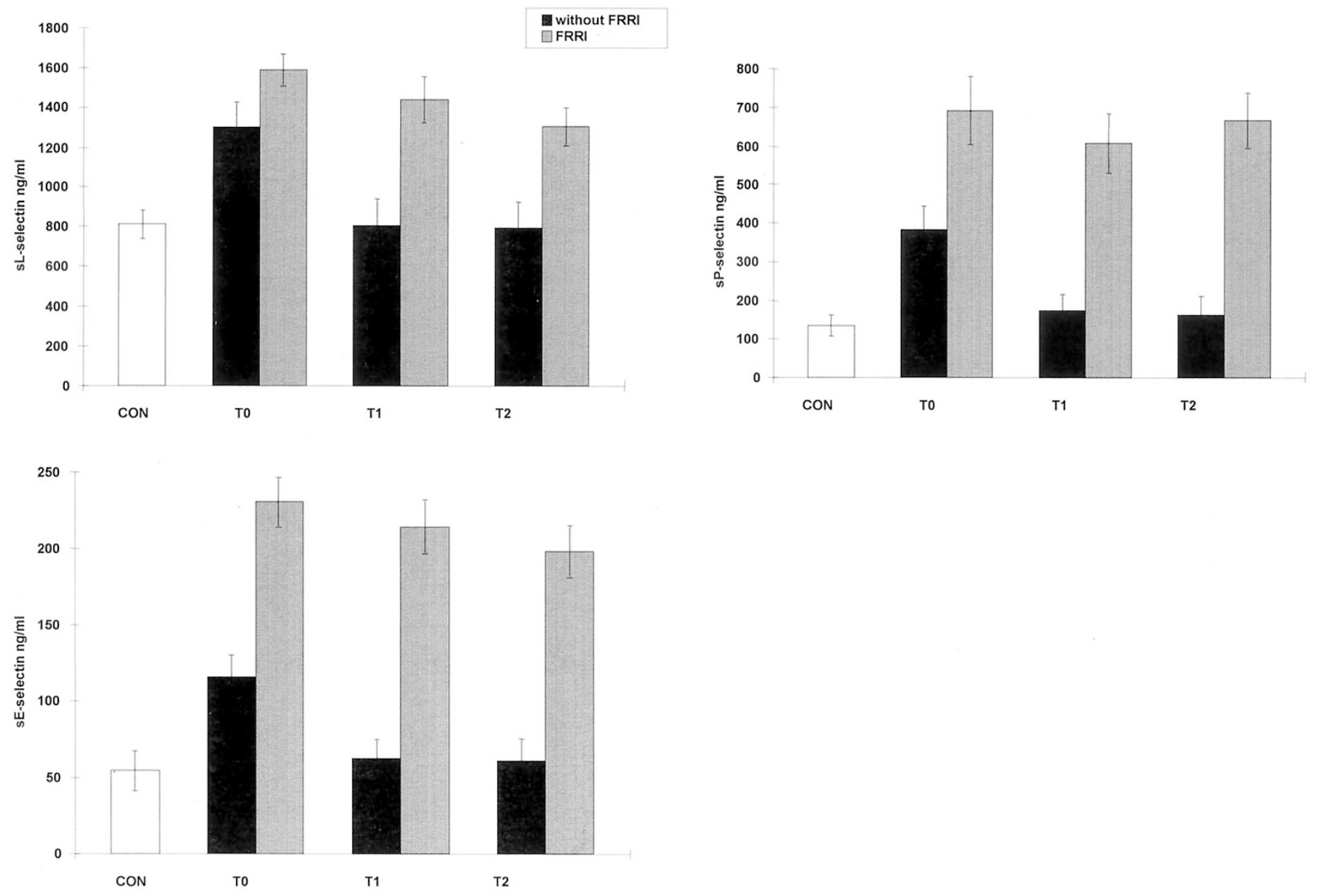

Figure 2. Circulating plasma levels of sL-selectin $(A)$, sE-selectin $(B)$, and sP-selectin $(C)$ in normal controls $(C O N)$ and in patients with and withoutFRRI) at acute phases $\left(\mathrm{T}_{0}\right)$, at $6 \mathrm{mo}\left(\mathrm{T}_{1}\right)$, and at $12 \mathrm{mo}\left(\mathrm{T}_{2}\right)$ when clinical symptoms of infection were resolved. The values are expressed as means $\pm \mathrm{SEM}$. 
elevated without reaching normal values (sICAM-1: $p=$ 0.0001 , and, s-VCAM-1: $p=0.001$ ). The comparison among $\mathrm{T}_{0}, \mathrm{~T}_{1}$, and $\mathrm{T}_{2}$ of plasmatic levels in patients with FRRI did not show significant differences.

At $\mathrm{T}_{0}$, in the group without recurrence, sICAM-1 and sVCAM-1 levels were significantly higher when compared with normal controls ( $p<0.0001$ and $p<0.038$, respectively) and decreased, reaching normal values during the follow-up. The comparison of plasma levels at $\mathrm{T}_{0}, \mathrm{~T}_{1}$, and $\mathrm{T}_{2}$ in the same group, showed statistically significant differences $(p=$ 0.0001).

When patients at $T_{0}, T_{1}$, and $T_{2}$ in both groups were compared, in the group of patients with FRRI we found significantly higher plasma levels of adhesion molecules than in those without recurrence $(p=0.0001)$.

Plasma IFN- $\gamma, I L-12, I L-4$, and IL-10 levels. Figure 4 shows plasma levels of IFN- $\gamma$ (Fig. 4A), IL-12 (Fig. 4B), IL-4 (Fig. 4C), and IL-10 (Fig. 4D) in patients with and without FRRI and in normal controls. At $\mathrm{T}_{0}, \mathrm{~T}_{1}$, and $\mathrm{T}_{2}$, plasma levels of IFN- $\gamma$ and IL-12 in patients with FRRI were slightly lower than in normal controls and no statistically significant differences were observed. No difference was found in the same group at $\mathrm{T}_{0}, \mathrm{~T}_{1}$, and $\mathrm{T}_{2}$. By contrast, at $\mathrm{T}_{0}, \mathrm{~T}_{1}$, and $\mathrm{T}_{2}$, the release of IL-4 and IL-10 increased significantly when compared with normal controls $(p=0.0001)$. No difference, for these cytokines, was found in the same group at $\mathrm{T}_{0}, \mathrm{~T}_{1}$, and $\mathrm{T}_{2}$.

In patients without recurrence, cytokine profile had a diametrically opposed trend; at $\mathrm{T}_{0}$, plasma levels of both IFN- $\gamma$ and IL-12 were significantly higher than in normal controls ( $p$ $=0.0001$ ). During the follow-up, these values returned to normal values. Moreover, at $\mathrm{T}_{1}$ and $\mathrm{T}_{2}$, cytokine levels were significantly lower $(p=0.0001)$ when compared with $\mathrm{T}_{0}$ values. At $\mathrm{T}_{0}, \mathrm{~T}_{1}$, and $\mathrm{T}_{2}$, plasma levels of both IL-4 and IL-10 were similar to controls. No differences, for these cytokines, were found in the same group at $\mathrm{T}_{0}, \mathrm{~T}_{1}$, and $\mathrm{T}_{2}$.

At $\mathrm{T}_{0}, \mathrm{~T}_{1}$, and $\mathrm{T}_{2}$, the comparison between both groups revealed that in patients with FRRI there were increased levels of IL-4 and IL-10 $(p=0.0001)$ and decreased levels of IFN- $\gamma$ and IL-12 at $\mathrm{T}_{0}(p=0.0001)$. During the follow-up, the levels of both IFN- $\gamma$ and IL-12 persisted at low levels and no statistically significant differences were found in both groups.

Relationship between plasma soluble CAM and cytokines. Table 3 shows correlations between soluble adhesion molecules and cytokines in children with FRRI. No correlations were found between plasma levels of IFN- $\gamma$, IL-12, and IL-10 and those of soluble adhesion molecules (sCAM), whereas plasma levels of IL-4 demonstrated statistically significant correlations with those of both sP-selectin and sVCAM-1. No statistically significant correlations were present among IL-4 plasma levels and those of sL-selectin, sE-selectin, and sICAM. The correlations among the various SCAM indicated that sE-selectin levels showed a significant correlation with sICAM-1 and sP-selectin with SVCAM-1. No correlations were found betwee the various soluble selectins, whereas significant correlations were found between plasma levels of both sICAM-1 and sVCAM-1. The relationship analysis among cytokines of Th-1/Th-2 response showed that IFN- $\gamma$ and IL-12 correlated positively each other $(\mathrm{r}=$
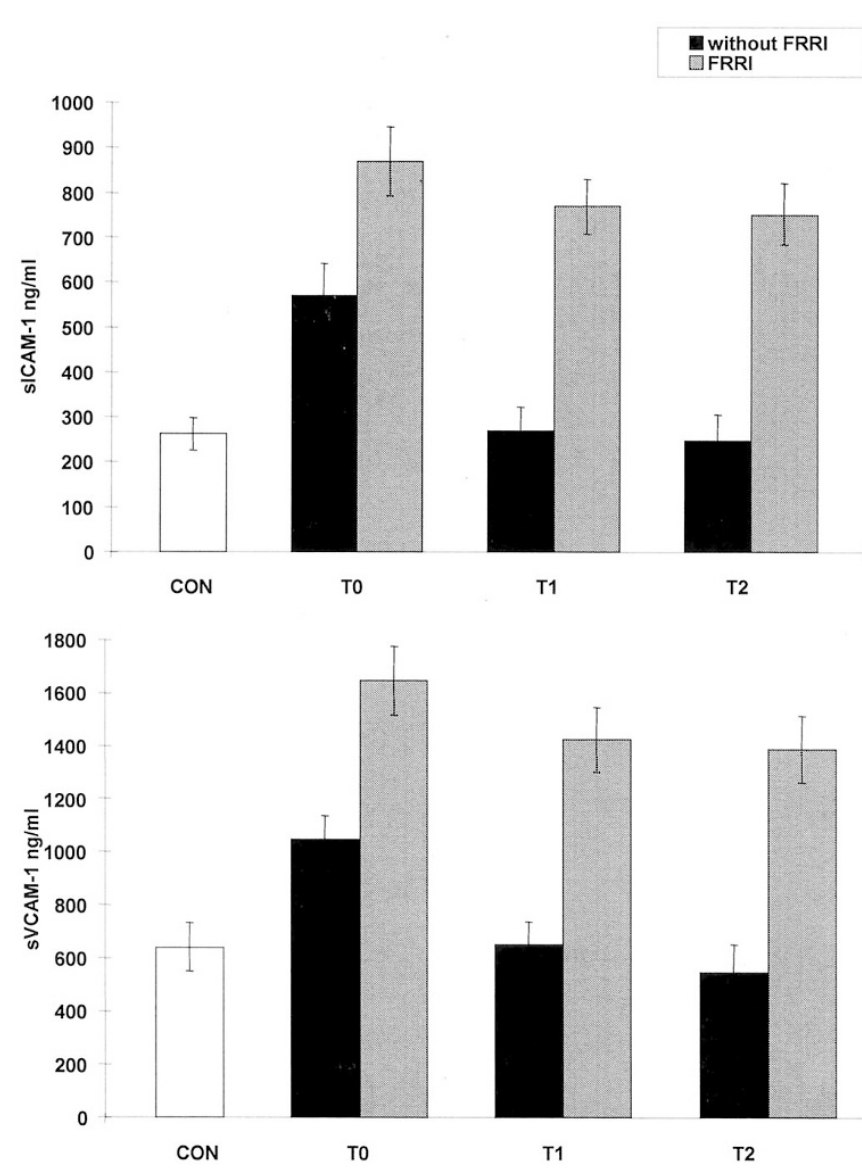

Figure 3. Circulating plasma levels of sICAM-1 $(A)$ and sVCAM-1 $(B)$ in normal controls $(C O N)$ and in patients with and without FRRI at acute phases $\left(\mathrm{T}_{0}\right)$, at $6 \mathrm{mo}\left(\mathrm{T}_{1}\right)$, and at $12 \mathrm{mo}\left(\mathrm{T}_{2}\right)$ when clinical symptoms of infection were resolved. The values are expressed as means \pm SEM.

$0.41, p=0.006)$, whereas a negative correlation was found between IFN- $\gamma$ and IL-4 $(r=-0.47, p=0.001)$. No correlations were present between IL-4 versus IL-12 or IL-10 plasma levels. A positive correlation was shown between IFN- $\gamma$ and IL-12 versus IL-10 $(r=0.42, p=$ $0.005 ; r=0.40, p=0.007$, respectively).

\section{DISCUSSION}

In this study, we examined whether soluble adhesion molecules, Th-1/Th-2 cytokines, and anomalies in the immune response to viral infections are associated with the recurrence of URTI. We showed, for the first time, important differences in mediator profile between the patients with and without FRRI in the monitoring phase of URTI. Our results showed that in children with or without FRRI, during the acute phase of infections, circulating sL-, sE-, and sP-selectins and plasma levels of sICAM-1 and SVCAM-1 were elevated when compared with those of normal controls. These plasma levels were higher in patients with FRRI when compared with patients without recurrence, and these values persisted at significant high levels during the follow-up, when clinical symptoms had already resolved; in patients without recurrence, they tended to be similar to normal controls. These results suggest that raised levels of sCAM, induced by viruses, could exacerbate and 

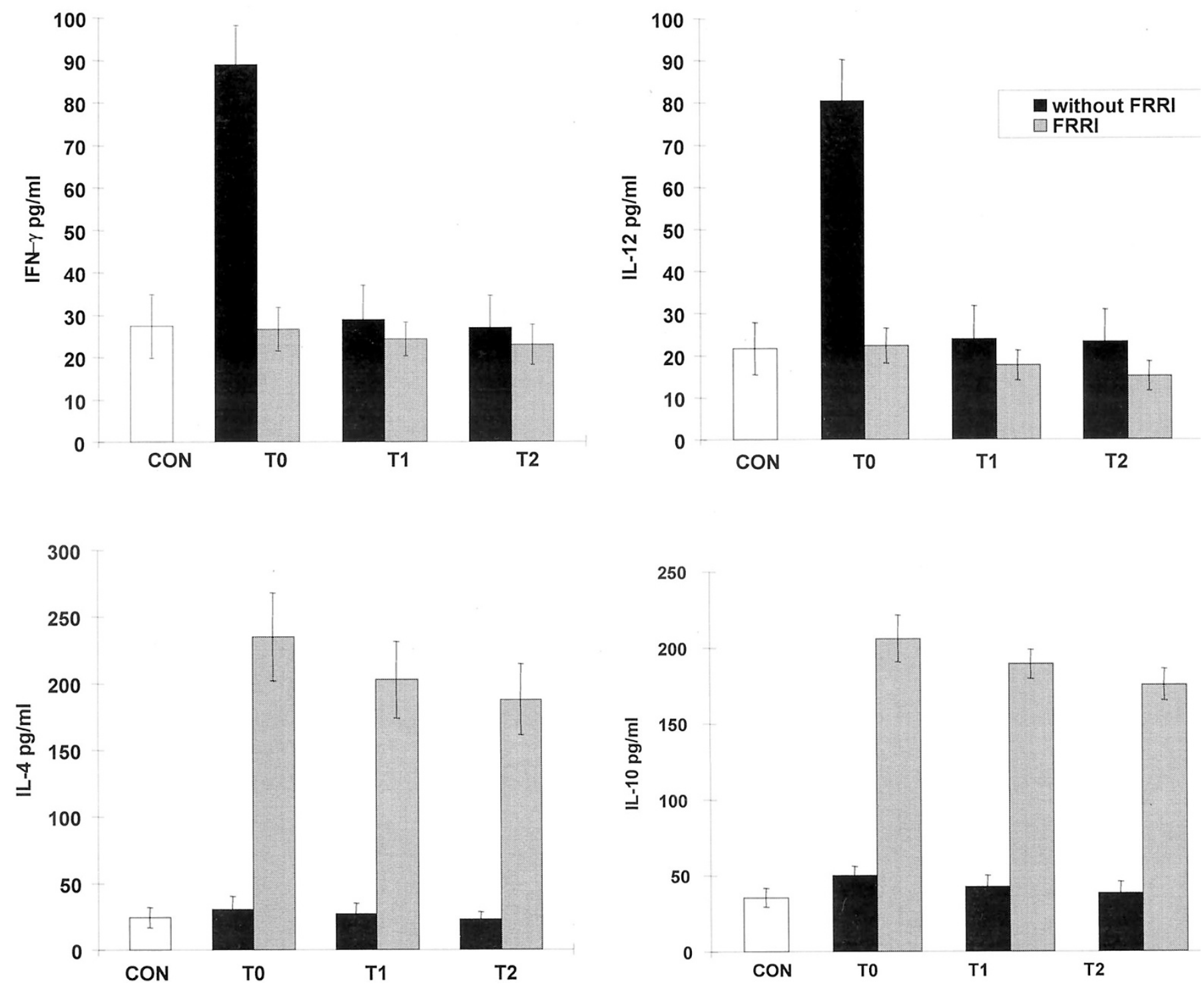

Figure 4. Circulating plasma levels of IFN- $\gamma(A)$, IL-12 (B), IL-4 $(C)$, and IL-10 $(D)$ in normal controls $(C O N)$ and in patients with and without FRRI at acute phases $\left(\mathrm{T}_{0}\right)$, at $6 \mathrm{mo}\left(\mathrm{T}_{1}\right)$, and at $12 \mathrm{mo}\left(\mathrm{T}_{2}\right)$ when clinical symptoms of infection were resolved. The values are expressed as means \pm SEM.

Table 3. Correlation among plasma levels of soluble adhesion molecules (sCAM), cytokines, and absolute leucocytes number in children

\begin{tabular}{|c|c|c|c|c|c|}
\hline & $\begin{array}{l}\text { sL-selectin } \\
(r \text { values })\end{array}$ & $\begin{array}{l}\text { sE-selectin } \\
(r \text { values })\end{array}$ & $\begin{array}{l}\text { sP-selectin } \\
(r \text { values })\end{array}$ & $\begin{array}{l}\text { sICAM-1 } \\
(r \text { values })\end{array}$ & $\begin{array}{l}\text { sVCAM- } 1 \\
(r \text { values })\end{array}$ \\
\hline IFN- $\gamma$ & $-0.12 \mathrm{NS}$ & $-0.20 \mathrm{NS}$ & $-0.15 \mathrm{NS}$ & $0.13 \mathrm{NS}$ & $0.02 \mathrm{NS}$ \\
\hline IL-4 & $0.20 \mathrm{NS}$ & $0.21 \mathrm{NS}$ & $0.48(<0.0001)$ & $-0.13 \mathrm{NS}$ & $0.60(<0.0001)$ \\
\hline IL-10 & $0.16 \mathrm{NS}$ & $0.16 \mathrm{NS}$ & $0.19 \mathrm{NS}$ & $0.25 \mathrm{NS}$ & $0.22 \mathrm{NS}$ \\
\hline sL-selectin & - & $0.03 \mathrm{NS}$ & $0.02 \mathrm{NS}$ & $0.03 \mathrm{NS}$ & $0.04 \mathrm{NS}$ \\
\hline sICAM-1 & $0.03 \mathrm{NS}$ & $0.53(<0.0001)$ & $0.20 \mathrm{NS}$ & - & $0.62(<0.0001)$ \\
\hline sVCAM-1 & $0.04 \mathrm{NS}$ & $0.24 \mathrm{NS}$ & $0.36(<0.001)$ & $0.62(<0.0001)$ & - \\
\hline Leucocytes number & $-0.19 \mathrm{NS}$ & $-0.22 \mathrm{NS}$ & $-0.57 \mathrm{NS}$ & $-0.46 \mathrm{NS}$ & $0.49 \mathrm{NS}$ \\
\hline
\end{tabular}

Plasma samples of 44 patients were analyzed in the various phases of infection: acute phases $(n=44)$ and during the follow-up when clinical symptoms of infection were resolved. Significance (P value) is indicated in parentheses.

prolong viral infection in children with recurrent URTI. It has been demonstrated that some viruses (ie adenovirus) may persist in a latent form in which viral proteins are produced without replication of a complete virus (21). Moreover, viral proteins, present in the airway epithelial cells, are known to regulate the expression of many genes by interacting with 
cellular transcription factors, enhancing the production of inflammatory mediators, as ICAM-1 activating ICAM-1promoter activity $(22,23)$. SCAM in our patients may be produced as a consequence of recurrent inflammation (a "bystander" effect), supported by a latent form of viruses and competing with cell surface forms for ligands, and may regulate the inflammatory response.

Plasma levels of sL-, sP-, and sE-selectin in patients with FRRI were also significantly more elevated than in those without frequent recurrence of URTI and in normal controls; a significant positive correlation was found between sE-selectin and sICAM-1 and between sP-selectin and sVCAM-1; no correlation with other adhesion molecules was found for sLselectin. No modification in the leukocyte count was found, suggesting that the elevated values of sCAM reflect neither an increase in the leukocytes population nor in its subsets. In parallel to sCAM, we analyzed Th-1-type (IL-12 and IFN- $\gamma$ ) and Th-2-type (IL-4 and IL-10) cytokines. Our results show that the virus-infected children with FRRI exhibit increased levels of IL- 4 and IL-10 and decreased release of IFN- $\gamma$ and IL-12.

Our in vivo observations indicate that the increased plasma levels of IL-4 and IL-10 induce a skewing into Th-2-type response and inhibit the differentiation into Th-1-type. These results are in agreement with previous reports of other authors in children affected by atopic airway diseases $(24,25)$. In addition, the increased IL-10 release down-regulates IFN- $\gamma$ and IL-12 production, inducing an immunologic unresponsiveness in children with FRRI. This could, in part, contribute to the frequent recurrence of URTI. On the other hand, IL-10 production was found to be associated in infants with increased risk of development of recurrent wheezing $(26,27)$. Although several studies have demonstrated that reduced IFN- $\gamma$ levels are a marker for higher risk of allergy (28), our patients did not show allergic symptoms despite of the reduced IFN- $\gamma$ levels.

More importantly, our results, in patients with FRRI, show a direct correlation between plasma levels of IL-4 and both sP-selectin and sVCAM-1; no correlations were found with sICAM-1 and sE-selectin. IL-4 is known to increase VCAM-1 protein levels by stabilization of VCAM-1 mRNA, and to inhibit ICAM-1 and E-selectin (29). The patients with FRRI showed elevated concentration of $\operatorname{IgG}$ caused by a sharp subclass increase in $\operatorname{IgG}_{1}$, whereas the $\operatorname{IgG}_{2}$ were lower in 29 out of $44(\sim 66 \%)$ children. Reduced plasma levels of IFN- $\gamma$ and $\mathrm{IgG}_{2}$ antibodies during the acute phase of the virus infection are consistent with the down-regulation of Th-1-type immunoresponse. On the other hand, the IL-12 reduction correlated well with the decreased levels of IFN- $\gamma$. IL-12 plays an important role in driving the immune response toward a Th-1 direction, which, together with IFN- $\gamma$, counteracts Th-2 activity in vivo (30). Furthermore, this reduced release of virus-induced IFN- $\gamma$, observed in children with FRRI, is in agreement with previous studies (31). As suggested by Pascual et al. (32), attenuated production of IFN- $\gamma$ seems to be related with loss of cytolytic T lymphocyte activity, and is in accordance with the recurrence of URTI in our patients. In addition, the decreased release could be secondary to a depressed monocyte function and could be responsible for a decrease in the IL- 12 and IFN- $\gamma$ plasma levels. This depressed monocyte function could be attributed to a chronic activation induced by recurrent viral infection with consequent exhaustion of these cells.

In this study, children suffering from FRRI present not only elevated soluble adhesion molecule levels but also a skewing of the Th-1-type response toward a Th-2-type, characterized by an increased IL- 4 and IL-10 release, triggering IFN- $\gamma$ downregulation and impairing host defenses against viral challenge. The resulting plasma levels of IL-4 and IL-10, showed in children with FRRI, may explain, at least in part, the deviation from a typical antiviral Th-1 response, as well as a debilitating inflammatory response rather than cell-mediated viral immunity. On the other hand, IL-4 causes the isotype switch to $\mathrm{IgG}_{1}$ and a marked delay in viral clearance (33). Therefore, although Th2-predominant T-cell response observed in children with FRRI is responsible for inflammatory microenvironment, the absence of IFN- $\gamma$ alone is not sufficient to alter the response to viruses infection.

\section{CONCLUSION}

We postulate that higher plasma levels of soluble adhesion molecules in children affected by FRRI, even after recovery, might be due to a persistent exposure of endothelial cells to a remaining inflammatory microenvironment. Moreover, the cytokine profile of these patients could give rise to a potentially higher susceptibility to infection, and an incomplete maturity of their immune system might contribute to the disease recurrence. However, it is important to consider the complexity of the adhesion molecule expression and the multiplicity of factors able to influence the immune response balance $(34,35)$. In conclusion, despite numerous studies of the risk factors of URTI, little is known about the factors that could predict susceptibility to URTI. The biologic significance of these findings remains to be fully understood and further investigations and long-term follow-up studies are necessary.

\section{REFERENCES}

1. Gupta BD, Parakh M, Arora A 2001 Management of community acquired respiratory infections. Indian J Pediatr 68 Suppl 2:S39-S49

2. Howel D, Webster S, Hayes J, Barton A, Donaldson L 2002 The impact of recurrent throat infection on children and their families. Fam Pract 19:242-246

3. Crowe Jr JE, Williams JV 2003 Immunology of viral respiratory tract infection in infancy. Paediatr Respir Rev 4:112-119

4. Daele J, Zicot AF 2000 Humoral immunodeficiency in recurrent upper respiratory tract infections. Some basic, clinical and therapeutic features. Acta Otorhinolaryngol Belg 54:373-390

5. Kulander L, Pauksens K, Venge P 2001 Soluble adhesion molecules, cytokines and cellular markers in serum in patients with acute infections. Scand J Infect Dis 33:290-300

6. McEver RP 1994 Selectins. Curr Opin Immunol 6:75-84

7. van de Stolpe A, van der Saag PT 1996 Intercellular adhesion molecule-1. J Mol Med 74:13-33

8. Carlos TM, Harlan JM 1994 Leukocyte-endothelial adhesion molecules. Blood $84: 2068-2101$

9. Cowley HC, Heney D, Gearing AJ, Hemingway I, Webster NR 1994 Increased circulating adhesion molecule concentrations in patients with the systemic inflammatory response syndrome: a prospective cohort study. Crit Care Med 22:651-657

10. Etzioni A 1996 Adhesion molecules - their role in health and disease. Pediatr Res 39:191-198

11. Gearing AJ, Hemingway I, Pigott R, Hughes J, Rees AJ, Cashman SJ 1992 Soluble forms of vascular adhesion molecules, E-selectin, ICAM-1, and VCAM-1: pathological significance. Ann N Y Acad Sci 667:324-331

12. Brandtzaeg P 1995 Immunocompetent cells of the upper airway: functions in normal and diseased mucosa. Eur Arch Otorhinolaryngol 252(suppl 1):S8-S21

13. Elias JA, Zitnik RJ 1992 Cytokine-cytokine interactions in the context of cytokine networking. Am J Respir Cell Mol Biol 7:365-367 
14. Dong C, Flavell RA 2001 Th1 and Th2 cells. Curr Opin Hematol 8:47-51

15. Billaud G, Peny S, Legay V, Lina B, Valette M 2003 Detection of rhinovirus and enterovirus in upper respiratory tract samples using a multiplex nested PCR. J Virol Methods 108:223-228

16. Marin J, Jeler-Kacar D, Levstek V, Macek V 2000 Persistence of viruses in upper respiratory tract of children with asthma. J Infect 41:69-72

17. Steininger C, Aberle SW, Popow-Kraupp T 2001 Early detection of acute rhinovirus infections by a rapid reverse transcription-PCR assay. J Clin Microbiol 39:129-133

18. Steininger C, Kundi M, Aberle SW, Aberle JH, Popow-Kraupp T 2002 Effectiveness of reverse transcription-PCR, virus isolation, and enzyme-linked immunosorbent assay for diagnosis of influenza A virus infection in different age groups. J Clin Microbiol 40:2051-2056

19. Daum LT, Canas LC, Schadler CA, Ujimori VA, Huff WB, Barnes WJ, Lohman KL 2002 A rapid, single-step multiplex reverse transcription-PCR assay for the detection of human H1N1, H3N2, and B influenza viruses. J Clin Virol 25:345-350

20. Corne JM, Green S, Sanderson G, Caul EO, Johnston SL 1999 A multiplex RT-PCR for the detection of parainfluenza viruses $1-3$ in clinical samples. J Virol Methods $82: 9-18$

21. Matsuse T, Hayashi S, Kuwano K, Keunecke H, Jefferies WA, Hogg JC 1992 Latent adenoviral infection in the pathogenesis of chronic airways obstruction. Am Rev Respir Dis 146:177-184

22. Higashimoto Y, Elliott WM, Behzad AR, Sedgwick EG, Takei T, Hogg JC, Hayashi S 2002 Inflammatory mediator mRNA expression by adenovirus E1A-transfected bronchial epithelial cells. Am J Respir Crit Care Med 166:200-207

23. Whiteman SC, Bianco A, Knight RA, Spiteri MA 2003 Human rhinovirus selectively modulates membranous and soluble forms of its intercellular adhesion molecule-1 (ICAM-1) receptor to promote epithelial cell infectivity. J Biol Chem 278:11954-11961

24. Hamelmann E, Wahn U, Gelfand EW 1999 Role of the Th2 cytokines in the development of allergen-induced airway inflammation and hyperresponsiveness. Int Arch Allergy Immunol 118:90-94

25. Joshi P, Shaw A, Kakakios A, Isaacs D 2003 Interferon-gamma levels in nasopharyngeal secretions of infants with respiratory syncytial virus and other respiratory viral infections. Clin Exp Immunol 131:143-147
26. Bont L, Heijnen CJ, Kavelaars A, van Aalderen WM, Brus F, Draaisma JT, Geelen SM, Kimpen JL 2000 Monocyte IL-10 production during respiratory syncytial virus bronchiolitis is associated with recurrent wheezing in a one-year follow-up study. Am J Respir Crit Care Med 161:1518-1523

27. Koopman LP, Savelkoul H, van Benten IJ, Gerritsen J, Brunekreef B, Neijens J 2003 Increased serum IL-10/IL-12 ratio in wheezing infants. Pediatr Allergy Immunol 14:112-119

28. Liao SY, Liao TN, Chiang BL, Huang MS, Chen CC, Chou CC, Hsieh KH 1996 Decreased production of IFN gamma and increased production of IL-6 by cord blood mononuclear cells of newborns with a high risk of allergy. Clin Exp Allergy 26:397-405

29. Iademarco MF, Barks JL, Dean DC 1995 Regulation of vascular cell adhesion molecule-1 expression by IL-4 and TNF-alpha in cultured endothelial cells. J Clin Invest 95:264-271

30. Sornasse T, Larenas PV, Davis KA, de Vries JE, Yssel H 1996 Differentiation and stability of T helper 1 and 2 cells derived from naive human neonatal CD4 $+\mathrm{T}$ cells, analyzed at the single-cell level. J Exp Med 184:473-483

31. Pitkaranta A, Nokso-Koivisto J, Jantti V, Takala A, Kilpi T, Hovi T 1999 Lowered yields of virus-induced interferon production in leukocyte cultures and risk of recurrent respiratory infections in children. J Clin Virol 14:199-205

32. Pascual DW, Walters N, Hillemeyer P 1998 Repeated intratracheal instillations of nonreplicating adenovirus 2 vector attenuate CTL responses and IFN-gamma production. J Immunol 160:4465-4472

33. Moran TM, Isobe H, Fernandez-Sesma A, Schulman JL 1996 Interleukin-4 causes delayed virus clearance in influenza virus-infected mice. J Virol 70:5230-5235

34. Bolte G, Mielck A, Meyer I, Stiller-Winkler R, Heinrich J 1999 Inverse social gradient of secondary immune response parameters in children. Rev Environ Health 14:135-143

35. Calderon-Garciduenas L, Devlin RB, Miller FJ 2000 Respiratory tract pathology and cytokine imbalance in clinically healthy children chronically and sequentially exposed to air pollutants. Med Hypotheses 55:373-378 